\title{
Corrigendum
}

Cold Spring Harb Protoc 2016; doi: 10.1101/pdb.prot090035

\section{Corrigendum: Combining the Dihydrofolate Reductase Protein-Fragment Complementation Assay with Gene Deletions to Establish Genotype-to-Phenotype Maps of Protein Complexes and Interaction Networks}

\author{
Guillaume Diss and Christian R. Landry
}

When this protocol was first published, the concentrations for the reagents in the recipe entitled "Amino Acid Mix (10×)" were expressed as $\mathrm{g} / \mathrm{mL}$, but they should have been expressed as $\mathrm{g} / \mathrm{L}$. The authors apologize for this error. The HTML version of the recipe (doi: 10.1101/pdb.rec090308) has been corrected, as has the current PDF version of the protocol. A corrected version of the recipe is also included below.

Amino Acid Mix (10x)

Amino acid or nucleobase Concentration $(10 \times)$

Adenine sulfate

$0.4 \mathrm{~g} / \mathrm{L}$

Uracil

$0.2 \mathrm{~g} / \mathrm{L}$

L-Tryptophan

$0.4 \mathrm{~g} / \mathrm{L}$

L-Histidine hydrochloride

$0.2 \mathrm{~g} / \mathrm{L}$

L-Arginine hydrochloride

$0.2 \mathrm{~g} / \mathrm{L}$

L-Tyrosine

$0.3 \mathrm{~g} / \mathrm{L}$

L-Leucine

L-Lysine hydrochloride

$0.6 \mathrm{~g} / \mathrm{L}$

L-Phenylalanine

$0.3 \mathrm{~g} / \mathrm{L}$

L-Glutamic acid

$0.5 \mathrm{~g} / \mathrm{L}$

L-Asparagine

$1.0 \mathrm{~g} / \mathrm{L}$

L-Valine

$1.0 \mathrm{~g} / \mathrm{L}$

L-Threonine

$1.5 \mathrm{~g} / \mathrm{L}$

L-Serine

$2.0 \mathrm{~g} / \mathrm{L}$

L-Methionine

$3.75 \mathrm{~g} / \mathrm{L}$

$0.2 \mathrm{~g} / \mathrm{L}$

Dissolve the amino acids from the list above (except those to be excluded from any dropout media) in distilled $\mathrm{H}_{2} \mathrm{O}$. Filter-sterilize, store at $4^{\circ} \mathrm{C}$, and protect from light.

(C) 2022 Cold Spring Harbor Laboratory Press

Cite this corrigendum as Cold Spring Harb Protoc; doi:10.1101/pdb.corr107813 
Corrigendum: Combining the Dihydrofolate Reductase Protein-Fragment Complementation Assay with Gene Deletions to Establish Genotype-to-Phenotype Maps of Protein Complexes and Interaction Networks

Guillaume Diss and Christian R. Landry

Cold Spring Harb Protoc; doi: 10.1101/pdb.corr107813

Email Alerting Receive free email alerts when new articles cite this article - click here. Service

Subject Browse articles on similar topics from Cold Spring Harbor Protocols. 